Published in final edited form as:

Angew Chem Int Ed Engl. 2017 December 11; 56(50): 16023-16027. doi:10.1002/anie.201709485.

\title{
Systemic Delivery of Bc12-Targeting siRNA by DNA Nanoparticles Suppresses Cancer Cell Growth
}

\author{
Mohammad Aminur Rahman ${ }^{+}$, \\ Department of Hematology and Medical Oncology, Winship Cancer Institute, Emory University, \\ 1365 Clifton Rd, Atlanta, GA 30322 (USA)
}

\section{Pengfei Wang ${ }^{+}$,}

Wallace H. Coulter Department of Biomedical Engineering, Georgia Institute of Technology and Emory University, 1760 Haygood Dr, Atlanta, GA 30322 (USA)

\section{Zhixiang Zhao}

Department of Hematology and Medical Oncology, Winship Cancer Institute, Emory University, 1365 Clifton Rd, Atlanta, GA 30322 (USA)

Department of Dermatology, Central South University, 932 Lushan S Rd, Yuelu Qu, Changsha, Hunan (China)

\section{Dongsheng Wang, Sreenivas Nannapaneni}

Department of Hematology and Medical Oncology, Winship Cancer Institute, Emory University, 1365 Clifton Rd, Atlanta, GA 30322 (USA)

\section{Chao Zhang, Zhengjia Chen}

Department of Biostatistics and Bioinformatics Shared Resource, Emory University, 1365 Clifton Rd, Atlanta, GA 30322 (USA)

\section{Christopher C. Griffith,}

Department of Pathology, Emory University, 1364 Clifton Rd, Atlanta, GA 30322 (USA)

\section{Selwyn J. Hurwitz,}

Department of Paediatrics, Emory University, 1760 Haygood Dr, Atlanta, GA 30322 (USA)

\section{Zhuo G. Chen,}

Department of Hematology and Medical Oncology, Winship Cancer Institute, Emory University, 1365 Clifton Rd, Atlanta, GA 30322 (USA)

\section{Yonggang Ke,}

Wallace H. Coulter Department of Biomedical Engineering, Georgia Institute of Technology and Emory University, 1760 Haygood Dr, Atlanta, GA 30322 (USA)

\section{Dong M. Shin}

\footnotetext{
dmshin@emory.edu, yonggang.ke@emory.edu.

${ }^{+}$These authors contributed equally to this work.

Conflict of interest

The authors declare no conflict of interest.

Supporting information for this article, including experimental details, can be found under: https://doi.org/10.1002/anie.201709485
} 
Department of Hematology and Medical Oncology, Winship Cancer Institute, Emory University, 1365 Clifton Rd, Atlanta, GA 30322 (USA)

Wallace H. Coulter Department of Biomedical Engineering, Georgia Institute of Technology and Emory University, 1760 Haygood Dr, Atlanta, GA 30322 (USA)

\section{Abstract}

Short interfering RNA (siRNA) is a promising molecular tool for cancer therapy, but its clinical success is limited by the lack of robust in vivo delivery systems. Rationally designed DNA nanoparticles (DNPs) have emerged as facile delivery vehicles because their physicochemical properties can be precisely controlled. Nonetheless, few studies have used DNPs to deliver siRNAs in vivo, and none has demonstrated therapeutic efficacy. Herein, we constructed a number of DNPs of rectangular and tubular shapes with varied dimensions using the modular DNA brick method for the systemic delivery of siRNA that targets anti-apoptotic protein Bcl2. The siRNA delivered by the DNPs inhibited cell growth both in vitro and in vivo, which suppressed tumor growth in a xenograft model that specifically correlated with Bcl2 depletion. This study suggests that DNPs are effective tools for the systemic delivery of therapeutic siRNA and have great potential for further clinical translation.

\section{Keywords}

Bcl2; cancer therapy; DNA nanotechnology; nanoparticles; siRNA delivery

Short interfering RNAs (siRNAs) are able to specifically silence mRNA translation, ${ }^{[1]}$ which has emerged as a promising therapeutic tool in targeted cancer therapy. ${ }^{[2]}$ However, limited success has been achieved in the systemic administration of siRNA ${ }^{[3]}$ because of a series of hurdles including kidney filtration, clearance by phagocytes, aggregation with serum proteins, and degradation by nucleases before reaching the target cells. ${ }^{[3 \mathrm{~b}, \mathrm{~d}]}$ Nano-carriers are promising tools for the targeted delivery of siRNAs, however, conventional delivery systems (for example, inorganic and organic nanoparticles) face significant challenges, such as toxicity and limited tuning capacity of particles physicochemical properties (for example, size, shape, and surface chemistry) to achieve optimal delivery effect. ${ }^{[4]}$ Therefore, the lack of an efficient and versatile siRNA delivery system is a critical issue in limiting its clinical translation. Structural DNA nanotechnology has unprecedented ability to construct DNA nanoparticles (DNPs) with well-controlled size, shape, and surface functionality, ${ }^{[5]}$ which have been utilized in a variety of fields, ${ }^{[6]}$ including drug delivery. ${ }^{[7]}$ The homogeneous and versatile nature of DNPs affords great potential for the systemic delivery of siRNAs. To our best knowledge, few studies have explored the use of DNPs for the in vivo delivery of siRNAs, though several reports on using DNA origami nanostructures for the systemic delivery of small molecule drugs (for example, doxorubicin) have been published. ${ }^{[7 j]}$ Lee et al. utilized a DNA tetrahedral structure for the tumor-targeted delivery of siRNAs silencing luciferase. ${ }^{[7 f]}$ However, no therapeutic efficacy (that is, tumor growth inhibition) was demonstrated in this study. Moreover, the reported small tetrahedral structure offers limited programmability in physicochemical properties, in comparison to the delicate structures designed by the DNA origami ${ }^{[5 b]}$ or DNA brick ${ }^{[5 c]}$ methods.

Angew Chem Int Ed Engl. Author manuscript; available in PMC 2020 May 28. 
Herein, we designed DNPs with rectangular or tubular shapes of varied dimensions using the modular DNA brick method and studied their cellular uptake in cancer cells to pinpoint the optimal design toward in vitro and in vivo siRNA delivery. DNA brick nanostructures are self-assembled from short DNA strands, and can achieve high yields of target structures. In addition, their modularity makes it relatively facile to design and construct multiple nanostructures of different sizes. These properties make the DNA brick method suitable for rapid screening studies toward identifying structures with potent delivery capabilities and holds better practical applicability because of its ease of preparation. This study focused on nanorectangles and nanotubes because DNA nanostructures of similar shapes have demonstrated robust capability for in vitro ${ }^{[7 b, e, h, i]}$ and in vivo ${ }^{[7 j]}$ delivery of cargos such as doxorubicin. ${ }^{[7 e, j]} \mathrm{Bcl} 2$ was targeted because the $\mathrm{Bcl} 2$ family are central regulators of programmed cell death. ${ }^{[8]}$ Overexpression of $\mathrm{Bcl} 2$ is implicated in tumor initiation, progression, and resistance to therapy. ${ }^{[9]}$

Eight DNPs were designed (Figure 1a and the Supporting Information, Figure S1 and Table S1), including a 6-helix-wide, 96-bp-long rectangle (6Hx96BP-Rect), a 6-helix-wide, 96-bplong tube (6Hx96BP-Tb), a 6Hx192BP-Rect, a 6Hx192BP-Tb, a 12Hx96BP-Rect, a 12Hx96BP-Tb, a 12Hx192BP-Rect, and a 12Hx192BP-Tb. As shown in Figure 1a and the Supporting Information, Figure S2, AFM images confirmed the successful assembly of DNPs with expected dimensions and morphologies. For the tubular structures, opened rectangular structures were observed occasionally, which may be attributed to the AFM sample preparation and tip interference during scanning. Native agarose gel electrophoresis verified the assembly of DNPs (Figure 1b). Discrete bands were observed for DNPs, with the larger ones exhibiting slower mobility, suggesting the formation of the designed structures. Single-stranded handles that protrude from the surface of DNPs were used for loading siBcl2 through hybridization between handles and overhangs extending from siBcl2 (Figure 1c). The successful loading of siBcl2 onto 6Hx96BP-Rect was confirmed by gel electrophoresis since the loading of siBcl2 led to slower mobility (Figure 1d). Cy5conjugated single-stranded DNAs were loaded by using the same strategy for the cellular uptake studies (Supporting Information, Figure S3). We also examined DNP resistance to nuclease digestion in $10 \%$ fetal bovine serum (FBS) at 378C with varied incubation times. All DNPs remained intact after $4 \mathrm{~h}$ of incubation, with larger DNPs surviving as long as $8 \mathrm{~h}$ (Supporting Information, Figure S4). Overall, DNPs exhibited strong resistance to nuclease digestion similar to that reported for DNA nano-structures, ${ }^{[7 a]}$ making them potentially suitable for siRNA delivery in vitro and in vivo.

We next examined the cellular internalization of DNPs in a small cell lung carcinoma (SCLC) cell line (DMS53) and a non-small cell lung carcinoma (NSCLC) cell line (H1299). Cy5-DNAs were anchored onto DNPs to track their cellular uptake (Figure S3). A timecourse study was conducted to compare the internalization efficiency of DNPs. Flow cytometry demonstrated that all DNPs, regardless of size or shape, had higher internalization efficiency than Cy5-DNA alone in both H1299 and DMS53 cells at all time points $\left({ }^{*} P<\right.$ 0.05), indicating that DNPs served as delivery vehicles to transport Cy5-DNA into cells (Figure 2a and the Supporting Information Figure S5). In general, small DNPs exhibited slightly higher internalization efficiency than large DNPs in both cell lines. To compare with Cy5-DNA-tagged DNPs, Cy5-conjugated siBc12 were loaded onto 6H×96BP-Rect. Flow 
cytometry revealed similar cell internalization efficiency, with siBcl2-loaded 6H×96BP-Rect having slightly lower uptake (Supporting Information, Figure S6), which may be caused by siBc12 s lower loading efficiency onto DNPs given its relatively larger size than Cy5-DNA (steric hindrance and electrostatic repulsion).

We then visualized the cellular uptake of DNPs by confocal microscopy (Figure $2 b$ and the Supporting Information, Figure S7). Strong Cy5 fluorescence was observed within the cytoplasm, indicating DNPs were successfully internalized into the cells. Both studies revealed that small DNPs accumulate in cells efficiently and could be considered a better vehicle for siRNA delivery. Scavenger receptors are known to mediate the endocytosis of nucleic acids structures in multiple mammalian cell lines. ${ }^{[9 \mathrm{c}]}$ To examine the involvement of scavenger receptors in the uptake of DNPs, polyinosine (Poly-I) was used to competitively bind and saturate scavenger receptors. All DNPs showed 90\% reduction upon Poly-I treatment (Figure 2c), indicating that scavenger receptors are critical for the uptake of DNPs by DMS53 cells. Based on cell internalization studies, $6 \mathrm{H} \times 96 \mathrm{BP}-$ Rect was selected for subsequent in vitro and in vivo delivery of siBcl2. We first examined whether the siBcl2 used in this study can specifically silence Bcl2 in DMS53 cells. In both western blotting and RT-PCR analysis (Supporting Information, Figure S8), siBcl2 showed significant silencing effect against Bcl2, while a control siRNA had no apparent effect, indicating the high specificity of siBcl2. DMS53 cells were then treated with varying concentrations of siBcl2loaded 6H×96BP-Rect. Western blotting showed that 6H×96BP-Rect loaded with siBcl2 can inhibit Bcl2 expression by up to $90 \%$ (Figure 2d). On the mRNA level, a circa $70 \%$ silencing efficiency was observed by RT-PCR (Figure 2e). 6H×96BP-Rect alone showed Bcl2 inhibition by western blotting but not by RT-PCR, implying that the DNPs might have certain unknown interactions with $\mathrm{Bcl} 2$ proteins. $6 \mathrm{H} \times 96 \mathrm{BP}-\mathrm{Rect}-\mathrm{siBcl} 2$ induced significant cell growth inhibition, which was not observed for vehicle or naked siBcl2 (Figure $2 \mathrm{f}, \mathrm{g}$ ).

The anti-cancer therapeutic potential of siBcl 2 delivered by $6 \mathrm{H} \times 96 \mathrm{BP}-\mathrm{Rect}$ was studied in mice bearing DMS53 tumor xenografts. Five groups of drugs were administered through the tail vein on days $1,4,8,11$, and 15 . Dosages were determined based on the siRNA amount. Significant tumor growth inhibition was observed in mice treated with $6 \mathrm{H} \times 96 \mathrm{BP}-\mathrm{Rect}-$ siBcl2 $\left(5 \mathrm{mgkg}^{-1}\right.$ or $\left.10 \mathrm{mgkg}^{-1}\right)$ relative to the three control groups (Figure $3 \mathrm{a}$ and the Supporting Information, Figure S9 and Table S2). After $17 \mathrm{~d}$, the average tumor size of mice treated with these two groups was significantly smaller (ca. 2 -fold, $* P<0.05$ ) than that of the control groups. Furthermore, there was no evidence of toxicity for any treatment as judged by body weight (Supporting Information, Figure S10), behavior of mice, or pathologic examination of major organs (Figure $3 \mathrm{~b}$ and the Supporting Information, Figure $\mathrm{S} 11)$. Immunohistochemical staining revealed a significant reduction in $\mathrm{Bcl} 2$ protein in tumor tissues treated with $6 \mathrm{H} \times 96 \mathrm{BP}-\mathrm{Rect}-\mathrm{siBcl} 2\left(5 \mathrm{mgkg}^{-1}\right.$ or $\left.10 \mathrm{mgkg}^{-1}\right)$, compared to controls (Figure $3 \mathrm{~b}, \mathrm{c}$ ). Tumors with reduced Bcl2 protein levels also exhibited growth suppression and elevated levels of apoptosis, as revealed by Ki67 staining and terminal deoxyribonucleotidyl transferase-mediated dUTP nick end labeling (TUNEL) assays (Figure $3 b, c)$, respectively. Overall, these results demonstrated that pharmacologically active amounts of siBcl2 were delivered to the cytoplasm of cells in the tumor using achievable doses of $6 \mathrm{H} \times 96 \mathrm{BP}-$ Rect-siBcl2 to knockdown $\mathrm{Bcl} 2$ protein, induce apoptosis, inhibit cell 
proliferation, and eventually suppress tumor growth, though DNPs may be subject to faster degradation profiles in vivo (Supporting Information, Figure S12).

In summary, our studies show that all DNPs exhibited efficient uptake in cancer cells. The siBcl 2 delivered by one DNP showed high efficiency as evidenced by circa $90 \%$ knockdown of Bcl2 protein, circa $70 \%$ silencing of Bcl2 mRNA, and subsequent cellular growth inhibition in vitro. More importantly, we demonstrated that systemic delivery of siBcl 2 in mice by 6 Hx96BP-Rect exhibited effective tumor growth inhibition and no toxicity. In the current work, DNPs have no targeting moieties to minimize off-target delivery of siRNAs to healthy tissues. The DNA nanoparticles enter cell using the scavenger receptors, there are possibilities to trigger release of various cytokines and immune stimulation. In conjunction with targeting ligands (for example, folic acid or transferrin), we believe DNP-based siRNA or other therapeutics delivery will continue to overcome barriers and play an important clinical role in future cancer therapy.

\section{Supplementary Material}

Refer to Web version on PubMed Central for supplementary material.

\section{Acknowledgements}

This work was supported by NCI grant R21EB022828-01A1 (D.M.S. and Y.K.), and Winship Invests grant from Emory University. We are thankful to Dr. Anthea Hammond for her assistance in critical reading and editing of the manuscript. This study was also supported in part by Integrated Cellular Imaging Core (Core Director, Adam Marcus, PhD) and Division of Animal Resources (Michael J. Huerkamp, DVM, DACLAM, Director, Division of Animal Resources) at Emory University.

\section{References}

[1]. Fire A, Xu S, Montgomery MK, Kostas SA, Driver SE, Mello CC, Nature 1998, 391, 806 - 811. [PubMed: 9486653]

[2]. a)Matzke MA, Birchler JA, Nat. Rev. Genet 2005, 6, 24 - 35; [PubMed: 15630419] b)Huppi K, Martin SE, Caplen NJ, Mol. Cell 2005, 17, 1 - 10. [PubMed: 15629712]

[3]. a)Davis ME, Zuckerman JE, Choi CH, Seligson D, Tolcher A, Alabi CA, Yen Y, Heidel JD, Ribas A, Nature 2010, 464, 1067 - 1070; [PubMed: 20305636] b)Castanotto D, Rossi JJ, Nature 2009, 457, 426 - 433; [PubMed: 19158789] c)Rahman MA, Amin AR, Wang X, Zuckerman JE, Choi CH, Zhou B, Wang D, Nannapaneni S, Koenig, Chen Z, Chen ZG, Yen Y, Davis ME, Shin DM, J. Controlled Release 2012, 159, 384 - 392;d)Pecot CV, Calin GA, Coleman RL, LopezBerestein G, Sood AK, Nat. Rev. Cancer 2011, 11, 59 - 67. [PubMed: 21160526]

[4]. a)Peer D, Karp JM, Hong S, Farokhzad OC, Margalit R, Langer R, Nat. Nanotechnol 2007, 2, 751 - 760; [PubMed: 18654426] b)Kanasty R, Dorkin JR, Vegas A, Anderson D, Nat. Mater 2013, 12, 967 - 977. [PubMed: 24150415]

[5]. a)Seeman NC, Nature 2003, 421, 427 - 431; [PubMed: 12540916] b)Rothemund PW, Nature 2006, 440, 297 - 302; [PubMed: 16541064] c)Ke YG, Ong LL, Shih WM, Yin P, Science 2012, 338, 1177 - 1183. [PubMed: 23197527]

[6]. a)Kuzyk A, Schreiber R, Fan ZY, Pardatscher G, Roller EM, Hogele A, Simmel FC, Govorov AO, Liedl T, Nature 2012, 483, 311 - 314; [PubMed: 22422265] b)Langecker M, Arnaut V, Martin TG, List J, Renner S, Mayer M, Dietz H, Simmel FC, Science 2012, 338, 932 - 936; [PubMed: 23161995] c)Green AA, Silver PA, Collins JJ, Yin P, Cell 2014, 159, 925 - 939; [PubMed: 25417166] d)Jungmann R, Avendano MS, Woehrstein JB, Dai M, Shih WM, Yin P, Nat. Methods 2014, 11, 313 - 318; [PubMed: 24487583] e)Sun W, Boulais E, Hakobyan Y, Wang WL, Guan A, Bathe M, Yin P, Science 2014, 346, 717;f)Knudsen JB, Liu L, Bank Kodal AL, Madsen M, Li 
Q, Song J, Woehrstein JB, Wickham SF, Strauss MT, Schueder F, Vinther J, Krissanaprasit A, Gudnason D, Smith AA, Ogaki R, Zelikin AN, Besenbacher F, Birkedal V, Yin P, Shih WM, Jungmann R, Dong M, Gothelf KV, Nat. Nanotechnol 2015, 10, 892 - 898; [PubMed: 26322946] g)Gopinath A, Miyazono E, Faraon A, Rothemund PWK, Nature 2016, 535, 401 - 00; [PubMed: 27398616] h)Shen C, Lan X, Lu X, Meyer TA, Ni W, Ke Y, Wang Q, J. Am. Chem. Soc 2016, 138, 1764 - 1767; [PubMed: 26824749] i)Urban MJ, Dutta PK, Wang P, Duan X, Shen X, Ding B, Ke Y, Liu N, J. Am. Chem. Soc 2016, 138, 5495 - 5498; [PubMed: 27082140] j)Zhan P, Dutta PK, Wang P, Song G, Dai M, Zhao SX, Wang ZG, Yin P, Zhang W, Ding B, Ke Y, ACS Nano 2017, 11, 1172 - 1179. [PubMed: 28056172]

[7]. a)Li J, Pei H, Zhu B, Liang L, Wei M, He Y, Chen N, Li D, Huang Q, Fan CH, ACS Nano 2011, 5, 8783 - 8789; [PubMed: 21988181] b)Schller VJ, Heidegger S, Sandholzer N, Nickels PC, Suhartha NA, Endres S, Bourquin C, Liedl T, ACS Nano 2011, 5, 9696 - 9702; [PubMed: 22092186] c)Walsh AS, Yin HF, Erben CM, Wood MJA, Turberfield AJ, ACS Nano 2011, 5, 5427 - 5432; [PubMed: 21696187] d)Douglas SM, Bachelet I, Church GM, Science 2012, 335, 831 - 834; [PubMed: 22344439] e)Jiang Q, Song C, Nangreave J, Liu XW, Lin L, Qiu DL, Wang ZG, Zou GZ, Liang XJ, Yan H, Ding BQ, J. Am. Chem. Soc 2012, 134, 13396 - 13403; [PubMed: 22803823] f)Lee H, Lytton-Jean AKR, Chen Y, Love KT, Park AI, Karagiannis ED, Sehgal A, Querbes W, Zurenko CS, Jayaraman M, Peng CG, Charisse K, Borodovsky A, Manoharan M, Donahoe JS, Truelove J, Nahrendorf M, Langer R, Anderson DG, Nat. Nanotechnol 2012, 7, 389 - 393; [PubMed: 22659608] g)Zhao YX, Shaw A, Zeng XH, Benson E, Nystrom AM, Hogberg B, ACS Nano 2012, 6, 8684 - 8691; [PubMed: 22950811] h)Yan J, Hu C, Wang P, Zhao B, Ouyang X, Zhou J, Liu R, He D, Fan C, Song S, Angew. Chem. Int. Ed 2015, 54, 2431 - 2435; Angew. Chem. 2015, 127, 2461 - 2465;i)Halley PD, Lucas CR, McWilliams EM, Webber MJ, Patton RA, Kural C, Lucas DM, Byrd JC, Castro CE, Small 2016, 12, 308 - 320; [PubMed: 26583570] j)Zhang Q, Jiang Q, Li N, Dai L, Liu Q, Song L, Wang J, Li Y, Tian J, Ding B, Du Y, ACS Nano 2014, 8, 6633 - 6643. [PubMed: 24963790]

[8]. Danial NN, Korsmeyer SJ, Cell 2004, 116, 205 - 219. [PubMed: 14744432]

[9]. a)Park D, Magis AT, Li R, Owonikoko TK, Sica GL, Sun SY, Ramalingam SS, Khuri FR, Curran WJ, Deng X, Cancer Res. 2013, 73, 5485 - 5496; [PubMed: 23824742] b)Khor LY, Moughan J, Al-Saleem T, Hammond EH, Venkatesan V, Rosenthal SA, Ritter MA, Sandler HM, Hanks GE, Shipley WU, Pollack A, Clin. Cancer Res 2007, 13, 3585 - 3590; [PubMed: 17575222] c)Juin P, Geneste O, Gautier F, Depil S, Campone M, Nat. Rev. Cancer 2013, 13, 455 - 465. [PubMed: 23783119] 
a
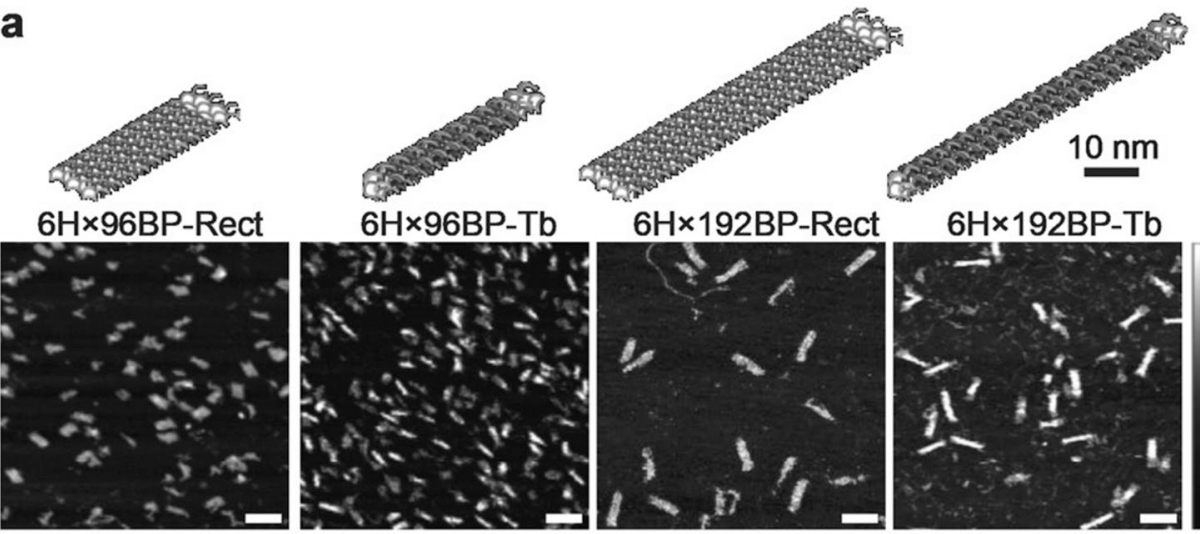

6H×96BP-Tb

6H×192BP-Rect
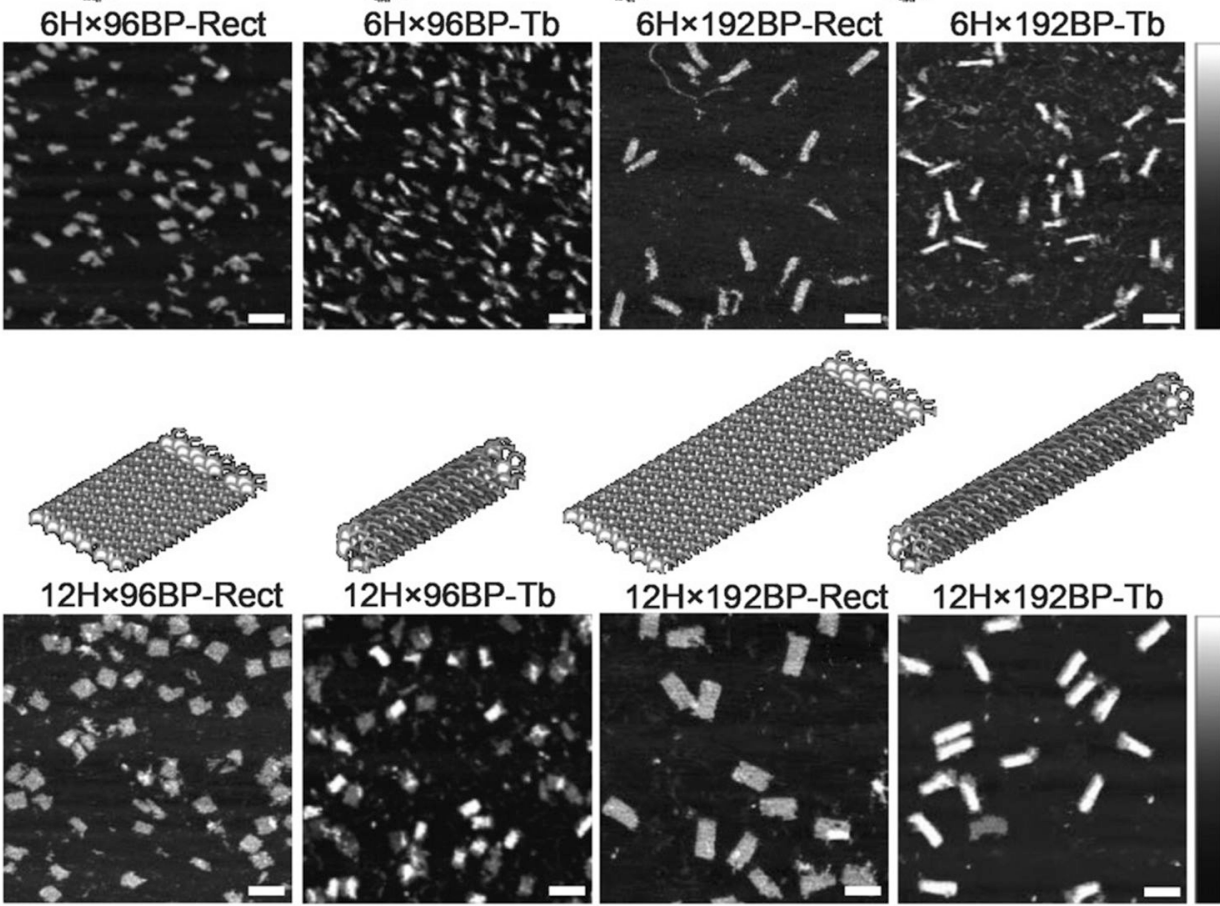

$12 \mathrm{H} \times 96 \mathrm{BP}-\mathrm{Tb}$

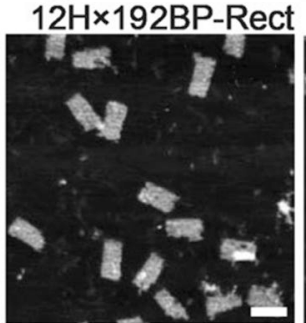

b

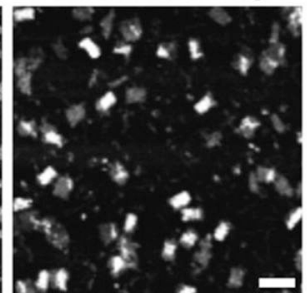

$12 \mathrm{H} \times 192 \mathrm{BP}-\mathrm{Tb}$

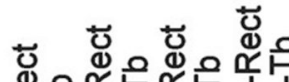

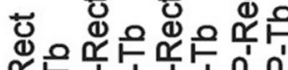

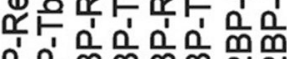

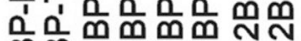
एक जे Фळळ

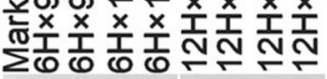
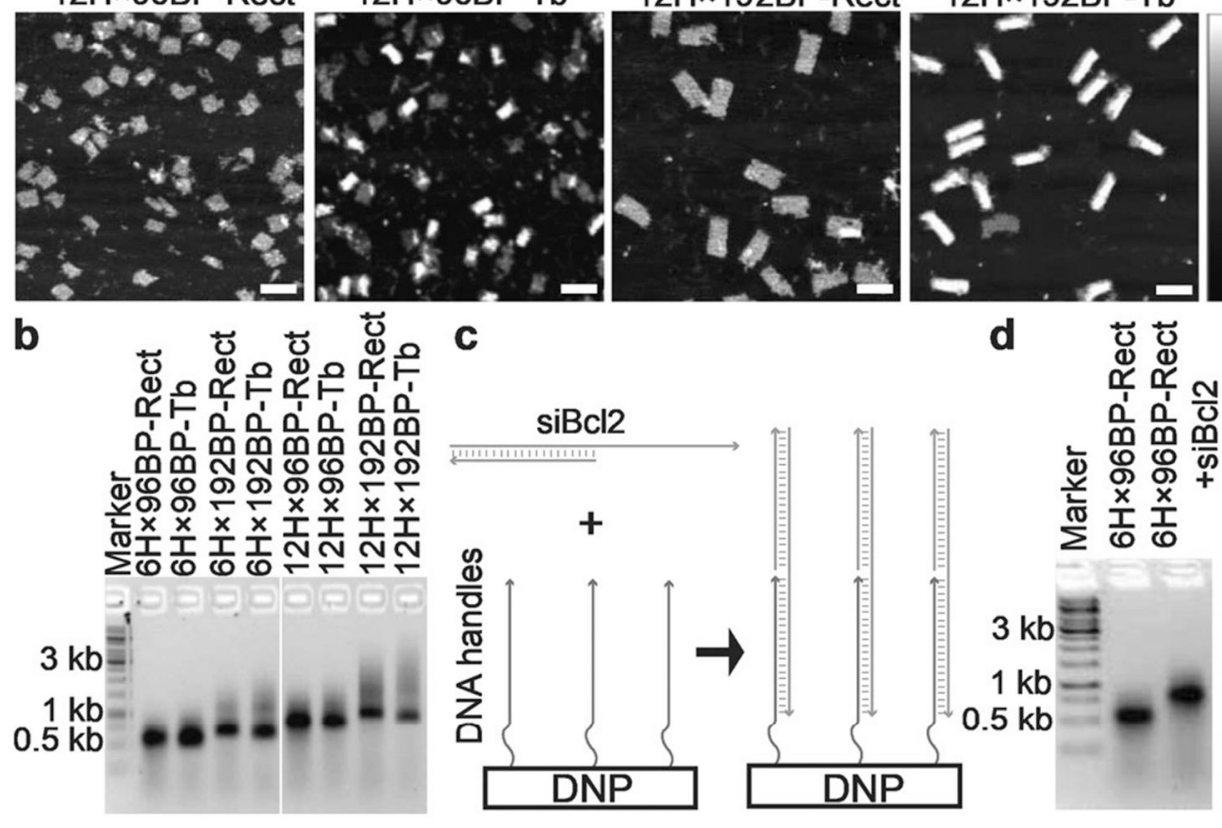

d

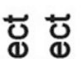

শั丶

i 产思鱼

竞 $\frac{x}{0}$

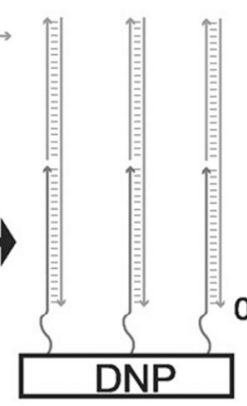

$3 \mathrm{~kb}$

$1 \mathrm{~kb}$ $0.5 \mathrm{~kb}$

Figure 1.

Design, construction, and characterization of DNPs. a) Schematics (top) and AFM images (bottom) of 8 DNPs. Scale bars $=50 \mathrm{~nm}$. Color bars are from -1 to $3 \mathrm{~nm}$ to indicate the height of DNPs. b) Native agarose gel electrophoresis of DNPs. Major distinct bands indicate the successful formation of DNPs with high yield. c) Loading mechanism of siBcl2 onto DNPs. siBcl2 are loaded through single-stranded handles extended from the surface of DNPs. d) Native agarose gel electrophoresis shows the successful loading of siBcl2 onto $6 \mathrm{H} \times 96 \mathrm{BP}-$ Rect as retarded mobility was observed after loading of siBcl2. 
a
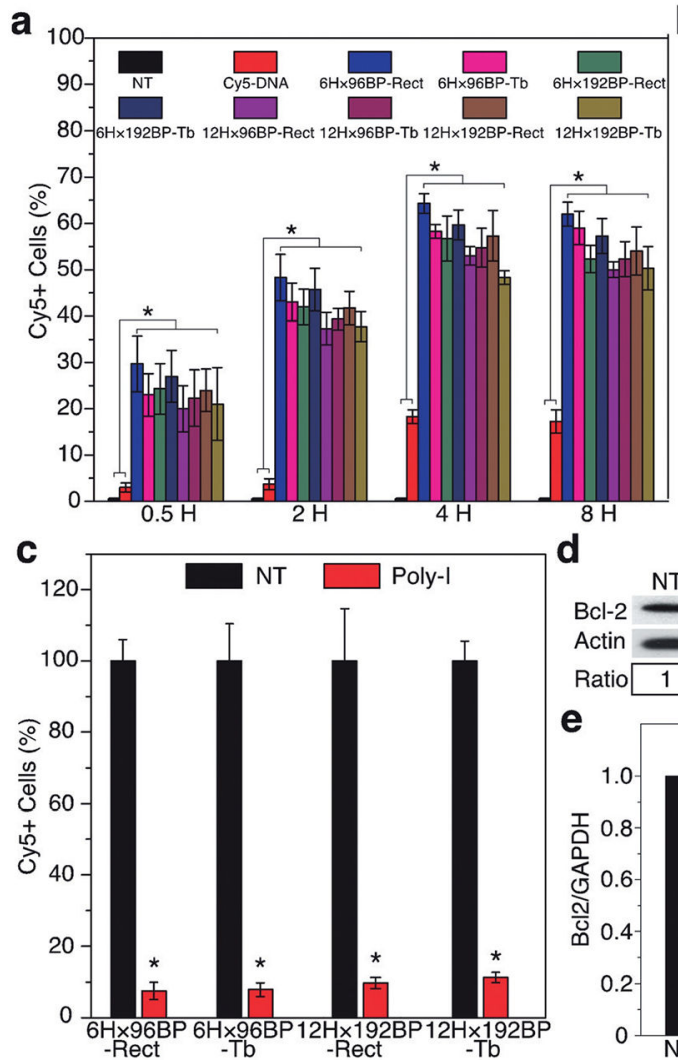

b $6 \mathrm{H} \times 96 \mathrm{BP}-$ Rect
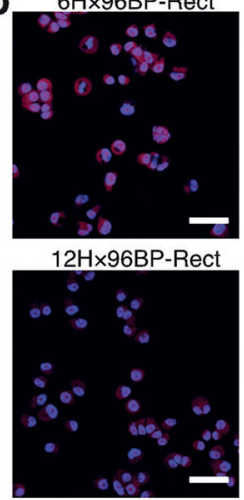

d

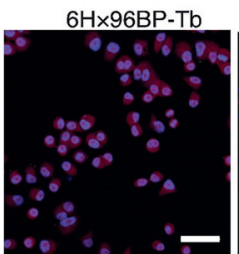

12H $\times 96 \mathrm{BP}-\mathrm{Tb}$

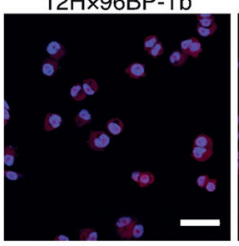

f
6H×192BP-Rect

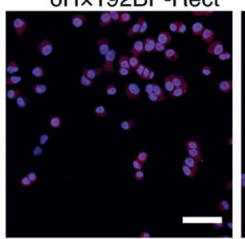

12H $\times 192 B P-R e c t$

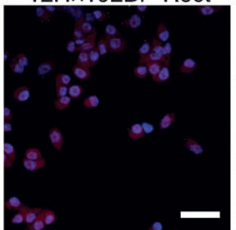

9

Figure 2.

Cellular internalization and growth inhibition of DNPs in DMS53 cells. a) Flow cytometry analysis of DNPs cellular uptake. Cells with no treatment (NT), Cy5-DNA as negative control, and eight different structures of DNPs-Cy5. DNP and Cy5 concentrations were 16.7 nм and 250 nм, respectively. All DNPs exhibited better uptake than controls, $* P<0.05$. b) Confocal microscopy imaging of cells treated with DNPs-Cy 5 for $8 \mathrm{~h}$. Red= Cy 5 fluorescence, blue $=$ nuclei stained with DAPI. Scale bars $=50 \mu \mathrm{m}$. c) Flow cytometry analysis of DNP uptake in cells treated with Poly-I, $* P<0.05$. d) Western blotting of Bcl2 expression in cells treated with no treatment $(\mathrm{NT})$; treatment $1,6 \mathrm{H} \times 96 \mathrm{BP}-$ Rect vehicle with concentration equivalent to treatment 6 ; treatment $2, \operatorname{siBcl} 2$ with concentration at $2.0 \mu \mathrm{M}$; treatments 3-6, 6H×96BP-Rect-siBcl2 with siBcl2 concentration at 0.3, 0.6, 1.2, and $2.0 \mu \mathrm{m}$. The relative ratio of $\mathrm{Bcl} 2$ and Actin is shown below the gel, which is normalized based on NT. The corresponding $6 \mathrm{H} \times 96 \mathrm{BP}$-Rect concentration is 25 -fold lower than the indicated siBcl 2 concentration because one $6 \mathrm{H} \times 96 \mathrm{BP}-\mathrm{Rect}$ loads $25 \mathrm{siBcl} 2$. e) Quantitative RT-PCR analysis of $\mathrm{Bcl} 2 \mathrm{mRNA}$ level. Treatments 5 and 6 have significantly better effects on silencing Bcl 2 mRNA than control groups, $* P<0.05$. f) Cell viability under different treatments. Scale bars $=200 \mu \mathrm{m}$. g) Quantitative analysis of cell viability. All data represent mean $\pm \mathrm{SD}(n=3)$. Cell-growth inhibition in treatments 5 and 6 are statistically significant compared to other groups, $* P<0.05$. 
a

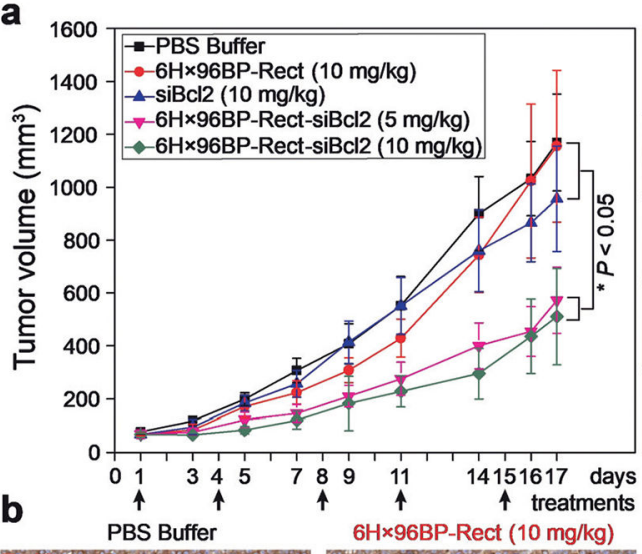

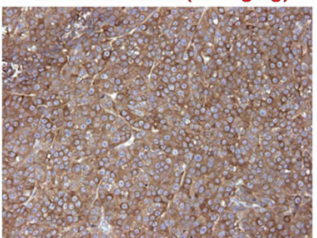
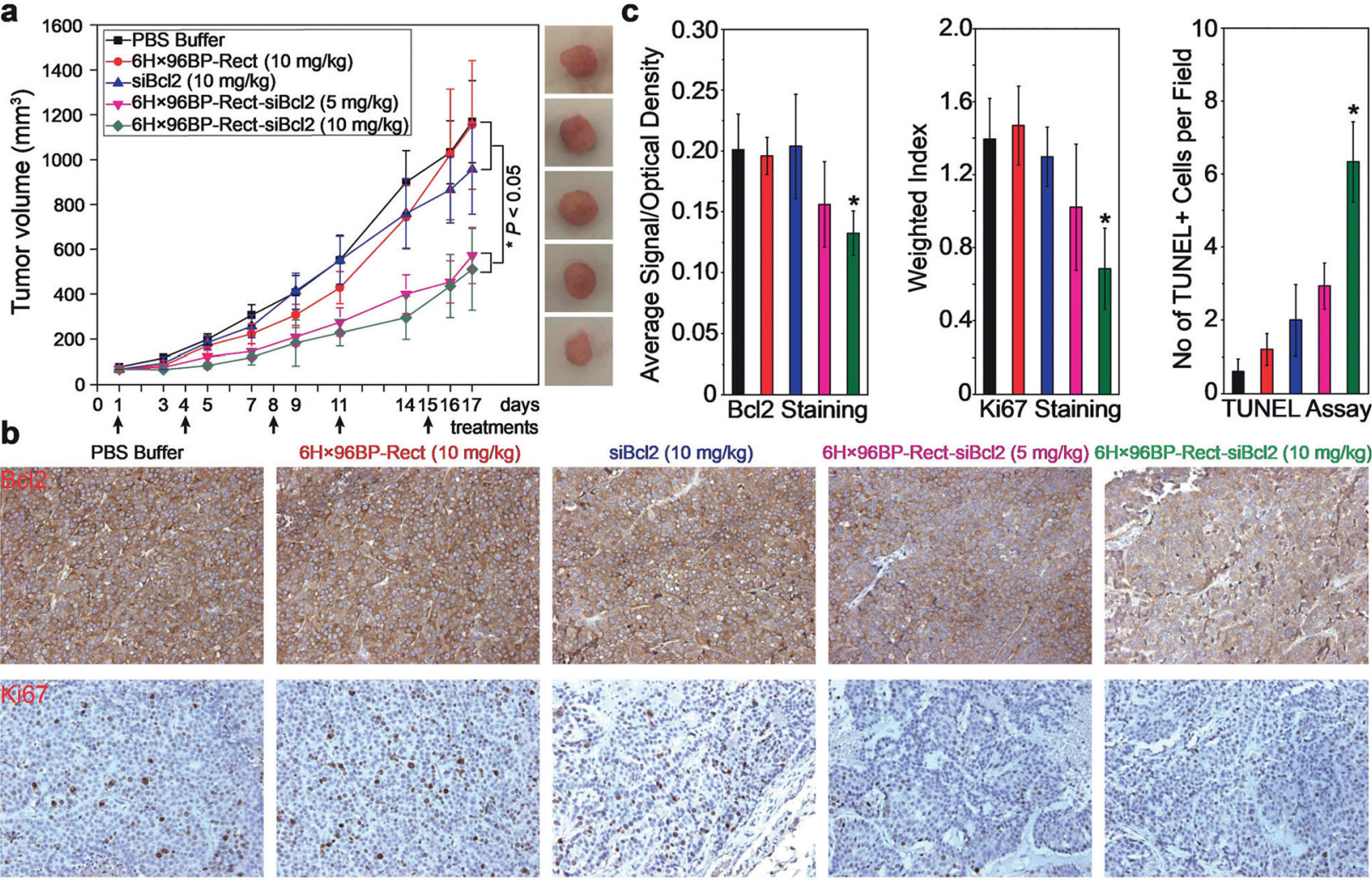

6H×96BP-Rect-siBcl2 (5 mg/kg) 6H×96BP-Rect-siBcl2 (10 mg/kg)
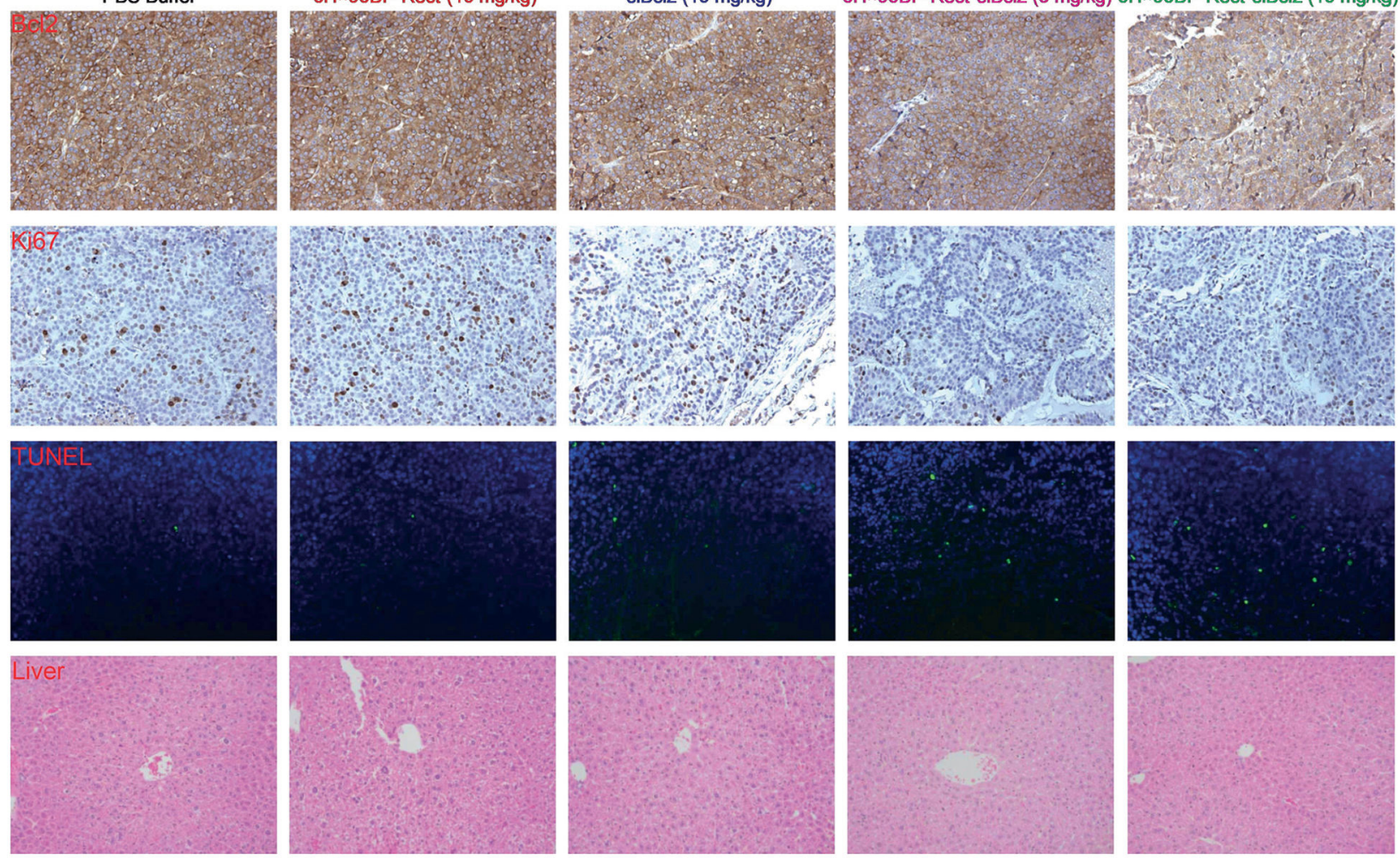

Figure 3.

Bcl2 knockdown-induced tumor-growth suppression in a xenograft tumor mice model by intravenous administration of $6 \mathrm{H} \times 96 \mathrm{BP}-\mathrm{RectsiBcl} 2$. a) Tumor growth curve of xenograft tumor-bearing mice. Five groups were studied including PBS buffer, $6 \mathrm{H} \times 96 \mathrm{BP}-\mathrm{Rect}$ alone (equivalent to $\left.10 \mathrm{mgkg}^{-1}\right)$, siBcl2 alone $\left(10 \mathrm{mgkg}^{-1}\right), 6 \mathrm{H} \times 96 \mathrm{BP}-\operatorname{Rect}-\mathrm{siBcl} 2\left(5 \mathrm{mgkg}^{-1}\right)$ and $6 \mathrm{H} \times 96 \mathrm{BP}-$ Rect-siBcl2 $\left(10 \mathrm{mgkg}^{-1}\right)$. Error bars are standard errors of five mice in each group. Representative photos of harvested tumors on day 17 are shown on the right, presented in the same order as the growth curves. b) Immunohistochemical and toxicity analysis. On day 17, mice were sacrificed. Tumor and major organs were processed for immunohistochemical (Bcl2 protein, Ki67, TUNEL) and H\&E stain, respectively.

Representative images from each group are shown. c) Quantitative analysis of immunohistochemical studies of tumor tissues. The color of the bar matches the color of 
labeling for each group as shown in (a, b). $6 \mathrm{H} \times 96 \mathrm{BP}-$ Rect-siBcl2 $\left(10 \mathrm{mgkg}^{-1}\right)$ performed statistically better than all other groups, ${ }^{*} P<0.05$. 